\title{
Repetitive Behavior
}

National Cancer Institute

\section{Source}

National Cancer Institute. Repetitive Behavior. NCI Thesaurus. Code C117193.

Recurring actions that are often non-purposeful. 